\title{
異常の伝搬遅れを利用する異常診断システム の診断精度の評価 ${ }^{\dagger}$
}

\author{
武田和宏・柴田望洋・柘植義文・松山久義 \\ 九州大学工学部 化学機械工学科 ${ }^{\dagger \dagger}$
}

異常診断システムの精度すなわち出力される原因の候 補の数を評価することは, 異常診断システムの設計のた めに必要であるばかりでなく, 対応措置の決定 ${ }^{4)}$, 测定 器の最適配置の決定のためにも不可欠である.

しかし，現状では，Iri ら ${ }^{2)}$ の符号付有向グラフを用い た異常診断法の精度 ${ }^{3)}$, および, 誤差を含んだ情報を利 用できるようにそれを改良した異常診断法の精度 ${ }^{5)}$ を評 価する方法が与えられているにすぎない.

一方, 診断対象システム内を異常が伝搬するのに必要 な時間遅れ（以下では, “異常の伝搬遅れ”之呼ぶ)を利 用する異常診断法が開発され ${ }^{1,6)}$, 異常診断実験によって 得られた個々のデータについては, Iri ら ${ }^{2)}$ の異常診断法 より精度が高いととが示されているが, 設計段階におい て精度を評価する方法は確立されていない。

ここでは, 異常の伝搬遅れを利用する診断法の精度を 評価する方法を提案し, 槽=配管系に適用して Iri ら ${ }^{2)} の$ 異常診断法の精度之比較する.

\section{異常の伝搬遅れを利用する異常診断}

システム内の状態変数を点に, 変数間の因果関係を有 向枝 (以下単に“枝”之呼ぶ) に対応させ, 因果関係が 「助長」であるとき“+”の符号を，「抑制」であるとき “-”の符号を枝の属性として与えた有向グラフを“符号 付有向グラフ”之呼ぶ.ささに, 符号付有向グラフの各 枝に伝搬遅れの大きさを“枝の長さ”として割り当てた あのを, “長さ・符号付有向グラフ”と呼ぶ.

測定変数に対応する点を“測定点”之呼び，測定され ていない变数に対応する点を“非測定点”之呼ぶ. 測定 変数 $x$ の正常值の上下にしきい值 $\gamma^{+}, r$ を設け, その変 数に対応する測定点に， $x>r^{+}$であるとき“+”を， $r^{+}$ $\geqq x \geqq r^{-}$のとき“0”を， $x<r^{-}$のとき“一”を与える. 測定点に与えられたてれらの“符号”の組み合わせを“3 段階パターン”之呼ぶ。 3 段階パターンは対象システム の状態を表す.

+または一の符号を持っている点を“有効点”之呼び， 有効な測定点を “有効測定点” と呼ぶ。また，ある枝の

† 1991年 8 月14日受理; 化学工学会大分大会 (大分, 1990年 11月）にて発表

†† 个 812 福岡市箱崎 6-10-1
符号が始点の符号と終点の符号の積に一致したとき，そ の枝を “有効枝”之呼ぶ. 有効点は異常を示す变数に対 応し，有効枝は異常を伝搬している可能性のある因果関 係に対応する。

異常の伝搬経路のモデルとして, “長さ付き有効道” を次のように定義する.

[定義 1] 長さ・符号付有向グラフ内の初等的な 有向道とそれに含まれる点の上の 3 段階パターンが与え られたとする．非測定点に“+”または“一”を与えてそ の有向道上の枝をすべて有効枝とすることができるとき， その有向道を “有効道”之呼ぶ.

さらに，有向道の長さを，それに含まれる枝の長さの 和と定義して, 任意の点から正常な測定点までの有向道 の長さの最小値を “非検出長さ”と呼ぶ. 有効道の中で その始点の非検出長さより短いものを “長さ付き有効道” と呼ぶ。ただし，正常な測定点への有向道が存在しない 点の非検出長さは無限大とする.（定義終り）

診断対象システム内の異常の伝搬遅れを正確に評価す ることは困難であり，必ず䛊差が含まれる。誤差による 誤診を防ぐために, 許容量 $d$ を導入して定義 1 を次のよ うに緩和する。なお，許容量 $d$ の合理的な決定法は， Tsuge ら) $^{6)}$ にって与えられている.

[定義 2] 定義 1 で定義される有効道の中で, そ の始点の非検出長さに許容量 $d$ を加えた長さよりあ短い， あのを“ $d$ に許容された長さ付き有効道”之呼ぶ.（定義 終り)

診断対象システム内の異常の伝搬状態のモデルを次の ように定義する.

[定義 3] ある点から全ての有効測定点へ $d$ に許 容された長さ付き有効道が存在するとき，その点とそれ らの $d$ に許容された長さ付き有効道で構成される木を“d に許容された長さ付き有効根付木”と呼び，その点を“就 に許容された長さ付き有効根付木の根”之呼ぶ。また， $d$ に許容された長さ付き有効根付木をすべて列挙したと き, それらの根とその符号の対の集合を“ $d$ に許容され た候補集合”之呼ぶ。（定義終り）

測定点上の 3 段階パターンに対して列挙された $d$ に許 容された候補集合が異常の原因の候補の集合である. 


\section{異常の伝搬遅れを利用した異常診断法の精度の評価}

異常診断の結果の精度は, 異常時に診断対象システム から得られる情報によって異なるので, 最悪の場合に得 られる候補集合の大きさによって異常診断法の精度を評 価する，最悪の場合に得られる $d$ 亿許容された候補集合 を“dに許容された最大候補集合”之呼び，次のように 定義する。

[ 定義 4] 長さ・符号付有向グラフとその中の測 定点の集合 $M$ および許容量 $d$ の值が与えられたとき， $M$ 上の任意の 3 段階パターンに対して得られる $d$ 亿許容さ れた候補集合の中で，他の $d$ 亿許容された候補集合の真 の部分集合にならないものを“ $d$ 亿許容された最大候補 集合”之呼ぶ。一般にMに対しててのような集合は複数 個存在するので，それらの全ての集合を $M$ に対する “ $d$ 飞許容された最大候補集合族”之呼ぶ。（定義終り）

測定点の集合 $M$ 上の出現可能なすべての 3 段階パ夕ー ンに対して異常診断を実行すれば， $d$ 亿許容された最大 候補集合族を求めることができる。しかし，測定点が $n$ 個存在すると， $M$ 上の出現可能な 3 段階パターンは $3^{n}$ 個存在するので，上記のような単純な列挙法で $d$ 亿許容 された最大候補集合族を求めることは事実上不可能である。

Shibata ら ${ }^{3)}$ は，3段階パターンと候補集合の間任成 立する関係を利用した分枝限定法により，Iri ら ${ }^{21}$ の異常 診断法の最大候補集合族を求めている。乙てでは，測定 点上の 3 段階パターンと $d$ 亿許容された候補集合とに次 の定理および系が成立することを利用して，Shibata ら ${ }^{3}$ 之同様の分枝限定法により $d$ 亿許容された最大候補集合 族を求める。 ただし， $N, M$ は，それぞれ，長さ・符号 付有向グラフの点，測定点の集合である.

[ 定理 ] 長さ・符号付有向グラフとその中の測定 点の集合 $M$ および許容量 $d$ の值が与えられたとき，少な くとも 1 個の有効な符号を含む $M$ 上の任意の 3 段階パ夕 一ンに対して $d$ に許容された候補集合 $C$ が得られたとす ると，いかなる点 $m(\in N, \notin M)$ を測定点に加え，それ にいかなる符号を与えても，異常診断によって得られる $d$ 亿許容された候補集合は $C$ の部分集合である.（定理 終り)

[系 ] 長さ・符号付有向グラフとその中の測定点 の集合 $M$ 拈よび許容量 $d$ の值が与えられたものとする. $M$ 上飞任意の $d$ 亿許容された長さ付き有効根付木を作る ことができないパターンが与えられたとき，任意の点 $m$ $(\in N$, $\notin M)$ を測定点に加えて適当な符号を与えること によって, $d$ 亿許容された長さ付き有効根木を作り得る ようにするてとはできない（系終り)

定理抢よび系の証明はAppendix に示す。

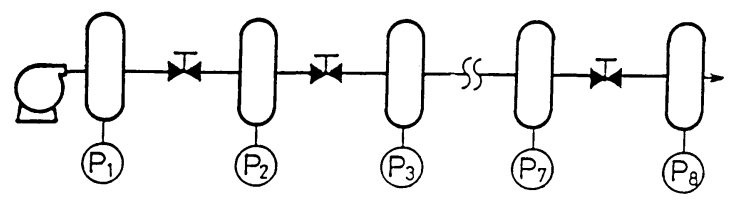

(a )

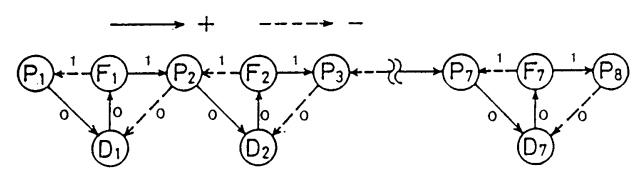

(b)

Fig. 1 Configuration of a serial tank-pipeline system and its weighted signed directed graph

\section{槽 $=$ 配管系への適用と考察}

Fig. 1(a) 亿示すような直列の槽＝配管系の長さ・符号 付有向グラフを Fig. 1(b) 亿示す. 压力 $\left(P_{i}\right)$ から差圧 $\left(D_{j}\right)$ への因果関係は数学的な関係であるので遅れは存在しな い. 流量 $\left(F_{i}\right)$ から压力 $\left(P_{j}\right)$ への因果関係は, タンクの容 積と流量とから決まる遅れを持っている．差压 $\left(D_{i}\right)$ 加 流量 $\left(F_{j}\right)$ への関係は流体力学的関係で, 厳密には気体の 慣性による遅れが存在するが，流量から压力への因果関 係の遅机に比べて十分小さいので無視する。したがって， 圧力から差圧への枝の長さ, 差圧から流量への枝の長さ は 0 とし, タンクの容量はすべて等しいものとして, 流 量から圧力への枝の長さは 1 とする.

この系において発生する異常の原因は，屯れ $\left(P_{i}-; i\right.$ $=1,2, \cdots, 8)$ 之配管のつまり $\left(F_{i}-; i=1,2, \cdots, 7\right)$ だけで あるとし, 压力 $\left(P_{i} ; i=1,2, \cdots, 8\right)$ だけを測定点とした ときの, $d$ 亿許容された最大候補集合族を Table 1 亿示 す.

$d=0$ の場合の $d$ 亿許容された最大候補集合が最む小 さく $d$ を大きくするにしたがって大きくなり,$d=\infty$ の場合は Iri ら ${ }^{2)}$ の異常診断法の最大 候補集合に一致す る.

乙の結果は, 個々の実験デー夕に関して異常の伝搬遅 れを利用する異常診断法の精度が，Iri ら ${ }^{2)}$ の異常診断法 の精度より屯高いという従来の結果と一致するので, $d$ 亿許容された最大候補集合が，異常の伝搬遅れを利用す る異常診断法の精度を表現する指標として適しているこ とを示している.

また， $d$ に許容された最大候補集合族の中に， $d$ の值 によって変化しない集合が 1 つ存在するが，乙れは，す べての測定点が “-”の符号を持つパターンが与えられた ときの候補集合であるため，非検出長さが無限大となる 
Table 1 Greatest sets of candidates utilizing allowance $d$ for the serial system

(a) $d=0$
1. $\mathrm{P} 1-\mathrm{P} 2-\mathrm{P} 3-\mathrm{P} 4-\mathrm{P} 5-\mathrm{P} 6-\mathrm{P} 7-\mathrm{P} 8-$
2. $\mathrm{P} 2-\mathrm{F} 1-$
3. $\mathrm{P} 3-\mathrm{F} 2-$
4. $\mathrm{P} 4-\mathrm{F} 3-$
5. $\mathrm{P} 5-\mathrm{F} 4-$
6. $\mathrm{P} 6-\mathrm{F} 5-$
7. $\mathrm{P} 7-\mathrm{F} 6-$
8. $\mathrm{P} 8-\mathrm{F} 7-$

(a) $d=1$
1. $\mathrm{P} 1-\mathrm{P} 2-\mathrm{P} 3-\mathrm{P} 4-\mathrm{P} 5-\mathrm{P} 6-\mathrm{P} 7-\mathrm{P} 8-$
2. $\mathrm{P} 2-\mathrm{P} 3-\mathrm{F} 1-$
3. $\mathrm{P} 3-\mathrm{P} 4-\mathrm{F} 2-$
4. $\mathrm{P} 4-\mathrm{P} 5-\mathrm{F} 3-$
5. $\mathrm{P} 5-\mathrm{P} 6-\mathrm{F} 4-$
6. $\mathrm{P} 6-\mathrm{P} 7-\mathrm{F} 5-$
7. $\mathrm{P} 7-\mathrm{P} 8-\mathrm{F} 6-$
8. $\mathrm{P} 8-\mathrm{F} 7-$

(b) $d=2$
1. $\mathrm{P} 1-\mathrm{P} 2-\mathrm{P} 3-\mathrm{P} 4-\mathrm{P} 5-\mathrm{P} 6-\mathrm{P} 7-\mathrm{P} 8-$
2. $\mathrm{P} 2-\mathrm{P} 3-\mathrm{P} 4-\mathrm{F} 1-$
3. $\mathrm{P} 3-\mathrm{P} 4-\mathrm{P} 5-\mathrm{F} 2-$
4. $\mathrm{P} 4-\mathrm{P} 5-\mathrm{P} 6-\mathrm{F} 3-$
5. $\mathrm{P} 5-\mathrm{P} 6-\mathrm{P} 7-\mathrm{F} 4-$
6. $\mathrm{P} 6-\mathrm{P} 7-\mathrm{P} 8-\mathrm{F} 5-$
7. $\mathrm{P} 7-\mathrm{P} 8-\mathrm{F} 6-$
8. $\mathrm{P} 8-\mathrm{F} 7-$

(c) $d=3$
1. $\mathrm{P} 1-\mathrm{P} 2-\mathrm{P} 3-\mathrm{P} 4-\mathrm{P} 5-\mathrm{P} 6-\mathrm{P} 7-\mathrm{P} 8-$
2. $\mathrm{P} 2-\mathrm{P} 3-\mathrm{P} 4-\mathrm{P} 5-\mathrm{F} 1-$
3. $\mathrm{P} 3-\mathrm{P} 4-\mathrm{P} 5-\mathrm{P} 6-\mathrm{F} 2-$
4. $\mathrm{P} 4-\mathrm{P} 5-\mathrm{P} 6-\mathrm{P} 7-\mathrm{F} 3-$
5. $\mathrm{P} 5-\mathrm{P} 6-\mathrm{P} 7-\mathrm{P} 8-\mathrm{F} 4-$
6. $\mathrm{P} 6-\mathrm{P} 7-\mathrm{P} 8-\mathrm{F} 5-$
7. $\mathrm{P} 7-\mathrm{P} 8-\mathrm{F} 6-$
8. $\mathrm{P} 8-\mathrm{F} 7-$

ためである。乙のようなととは, すべての診断対象シス テムについて起こることではないが，異常の伝搬遅れを 利用する異常診断法の限界を示しており, 今後の改良が 望まれる.

\section{Appendix}

\section{【定理の証明】}

題意により，Mに含まれる全ての有効点と $d$ 亿許容された長 さ付き有効道で結ばれる全ての点の集合が $C$ である，Mに含ま れない点 $m$ を測定点に加えることにより， $c \notin C$ が新たに原 因の候補に加わったと仮定する，点 $m$ を測定点に加えると，そ の符号により次のような場合分けが可能である。

場合 $\mathrm{A}$ ：点 $m$ の符号が有効な符号である場合

場合 $\mathrm{B}$ ：点 $m$ の符号が “ 0 ”である場合

[場合 A ] この場合には, 非検出長さは変化していない ので, $m$ を測定点とした後に成立する $d$ に許容された長さ付 き有効道は, 必ず, $m$ を測定点とする前に屯 $d$ 亿許容された 長さ付き有効道であったはずである. (d) $d=4$

$$
\begin{aligned}
& \text { 1. } \mathrm{P} 1-\mathrm{P} 2-\mathrm{P} 3-\mathrm{P} 4-\mathrm{P} 5-\mathrm{P} 6-\mathrm{P} 7-\mathrm{P} 8- \\
& \text { 2. } \mathrm{P} 2-\mathrm{P} 3-\mathrm{P} 4-\mathrm{P} 5-\mathrm{P} 6-\mathrm{F} 1- \\
& \text { 3. } \mathrm{P} 3-\mathrm{P} 4-\mathrm{P} 5-\mathrm{P} 6-\mathrm{P} 7-\mathrm{F} 2- \\
& \text { 4. } \mathrm{P} 4-\mathrm{P} 5-\mathrm{P} 6-\mathrm{P} 7-\mathrm{P} 8-\mathrm{F} 3- \\
& \text { 5. } \mathrm{P} 5-\mathrm{P} 6-\mathrm{P}-\mathrm{P} 8-\mathrm{F} 4- \\
& \text { 6. } \mathrm{P} 6-\mathrm{P} 7-\mathrm{P} 8-\mathrm{F} 5- \\
& \text { 7. } \mathrm{P} 7-\mathrm{P} 8-\mathrm{F} 6- \\
& \text { 8. }
\end{aligned}
$$

(e) $d=5$

$$
\begin{aligned}
& \text { 1. } \mathrm{P} 1-\mathrm{P} 2-\mathrm{P} 3-\mathrm{P} 4-\mathrm{P} 5-\mathrm{P} 6-\mathrm{P} 7-\mathrm{P} 8- \\
& \text { 2. } \mathrm{P} 2-\mathrm{P} 3-\mathrm{P} 4-\mathrm{P} 5-\mathrm{P} 6-\mathrm{P} 7-\mathrm{F} 1- \\
& \text { 3. } \mathrm{P} 3-\mathrm{P} 4-\mathrm{P} 5-\mathrm{P} 6-\mathrm{P} 7-\mathrm{P} 8-\mathrm{F} 2- \\
& \text { 4. } \mathrm{P} 4-\mathrm{P} 5-\mathrm{P} 6-\mathrm{P} 7-\mathrm{P} 8-\text { F3- } \\
& \text { 5. P5- P6- P7- P8- F4- } \\
& \text { 6. P6- P7- P8- F5- } \\
& \text { 7. P7- P8- F6- } \\
& \text { 8. P8- F7- }
\end{aligned}
$$

(f) $d=\infty$
1. $\mathrm{P} 1-\mathrm{P} 2-\mathrm{P} 3-\mathrm{P} 4-\mathrm{P} 5-\mathrm{P} 6-\mathrm{P} 7-\mathrm{P} 8-$
2. $\mathrm{P} 2-\mathrm{P} 3-\mathrm{P} 4-\mathrm{P} 5-\mathrm{P} 6-\mathrm{P} 7-\mathrm{P} 8-\mathrm{F} 1-$
3. $\mathrm{P} 3-\mathrm{P} 4-\mathrm{P} 5-\mathrm{P} 6-\mathrm{P} 7-\mathrm{P} 8-\mathrm{F} 2-$
4. $\mathrm{P} 4-\mathrm{P} 5-\mathrm{P} 6-\mathrm{P} 7-\mathrm{P} 8-\mathrm{F} 3-$
5. $\mathrm{P} 5-\mathrm{P} 6-\mathrm{P} 7-\mathrm{P} 8-\mathrm{F} 4-$
6. $\mathrm{P} 6-\mathrm{P} 7-\mathrm{P} 8-\mathrm{F} 5-$
7. $\mathrm{P} 7-\mathrm{P} 8-\mathrm{F} 6-$
8. $\mathrm{P} 8-\mathrm{F} 7-$

$m$ を測定点とした後で, $c$ が $d$ 亿許容された長さ付き有効根 付木の根となるには， $c$ あまた Mに含まれる全ての有効点と $d$ に許容された長さ付き有効道によって結ばれなければならない. $c$ が $M$ に含まれる全ての有効点と $d$ 亿許容された長さ付き有 効道で結ばれるのであれば, $m$ を測定点に加える前においても $c$ は $M$ に含まれる全ての有効点之 $d$ に許容された長さ付き有 効道で結ばれていたはずである。したがって， $c \in C$ でなけれ ばならず， $c \notin C$ の仮定と矛盾する.

[場合 B] 乙の場合には, 非検出長さは変化しない加短 くなるので， $m$ を測定点とする前に成立した $d$ に許容された長 さ付き有効道は， $m$ を測定点とした後では必ずしも $d$ に許容さ れた長さ付き有効道とはならないが， $m$ を測定点とした後に成 立する $d$ に許容された長さ付き有効道は, 必ず, $m$ を測定点之 する前にもdに許容された長さ付き有効道であったはずである。

したがって, 場合 $\mathrm{A}$ と同様の理由により, $c \notin C$ の仮定と矛

盾する結論が導かれる。(証明終り)

【系の証明】

［定理］に扔いて $C=\phi$ とした場合に相当するので明らかで ある。(証明終り) 


\section{Nomenclature}

$C=$ set of candidates

$D_{i}=$ node corresponding to pressure drop in the tank-pipeline system

$d=$ tolerance limit

$F_{i}=$ node corresponding to flow rate in the tank-pipeline system

$M=$ set of observed nodes in the weighted signed directed graph

$N=$ set of nodes in the weighted signed directed graph

$P_{i}=$ node corresponding to pressure in the tank-pipeline system

\section{Literature cited}

1) Gujima, F., B. Shibata, Y. Tsuge, H. Matsuyama and E. O'Shima: Kagaku Kogaku Ronbunshu, 16, 899 (1990)

2) Iri, M., K. Aoki, E. O'Shima and H. Matsuyama: J. Oper. Res. Soc. Japan, 23, 295 (1980)

3) Shibata, B. and H. Matsuyama: Kagaku Kogaku Ronbunshu, 15, 385 (1989)

4) Shibata, B., Y. Tsuge and H. Matsuyama: ibid., 16, 882 (1990)

5) Tateno, S., B. Shibata, Y. Tsuge and H. Matsuyama : ibid., 19, 30 (1993)

6) Tsuge, Y., J. Shiozaki, H. Matsuyama, E. O'Shima, Y. Iguchi, M. Fuchigami and M. Matsushita: ibid., 10, 531 (1984)

\title{
Evaluation of Accuracy of a Fault Diagnosis System Utilizing Transfer Delay of the Failure
}

\author{
Kazuhiro Takeda, BohYoh Shibata, Yoshifumi Tsuge \\ and Hisayoshi Matsuyama
}

Dept. of Chem. Eng., Kyushu Univ., Fukuoka 812

Key Words : Systems Engineering, Fault Diagnosis, Graph Theory, Weighted Signed Directed Graph, Evaluation of Accuracy

A method of evaluating the accuracy of fault diagnosis based on a weighted signed directed graph with delay is described. A tank-pipeline system is taken as an example to show the usefulness of this method and the influence of the value of allowance on the accuracy of fault diagnosis.

\section{流体振動による気泡塔内の液の軸方向混合特性の変化 ${ }^{\dagger}$ \\ 高橋憲司 ${ }^{*}$ 鍛治宗義・森茂・谷本 明 \\ 金沢大学工学部 物質化学工学科 ${ }^{\dagger \dagger}$}

Harbaum とHoughton ${ }^{3)}$ は気泡塔による炭酸ガスの吸 収実験を行い，振動を付加した場合に液相容量係数が 40 \%も増加したと報告している. 気泡塔内の液の混合特性

† 1992年 4 月13日受理 ; 化学工学会第 23 回秋季大会 (金沢, 1990年10月）にて一部発表

†† 920 金沢市小立野 2-40-20

* 北海道大学工学部 原子工学科
は気泡の運動に大きく影響されることを考えると， Harbaum とHoughtonの流体に振動を与えた実験では， 容量係数の増大のみならず液混合特性も大きく変化して いると予想されるがこの点に関する研究を見いだすとと はできない。本研究では, 液の軸方向混合拡散に及ぼす 振動の効果を, 標準気泡塔と多段気泡塔について検討し た. 